\title{
Aplicación de la terminología nanda-noc-nic en un paciente trasplantado de páncreas riñón
}

\author{
Consuelo Pérez Rincón, Eufemiano Pérez del Río \\ Unidad de diálisis peritoneal. Nefrología. Complejo Asistencial Universitario de Salamanca. España
}

\section{Introducción}

La Diabetes Mellitus (DM), es una epidemia mundial que se cifra en 190.000 .000 de casos, 330.000 .000 se prevén en 2025, produce 3.200 .000 muertes al año 0 lo que es lo mismo 6 muertos por minuto. En España hay 3.400.000 diabéticos, y esta cifra aumenta a un ritmo del $5 \%$ al año, y en nuestra comunidad de CastiIla y León se contabilizan 200.000 pacientes con esta patología. La DM es la principal causa de ceguera y de insuficiencia renal crónica (IRC) en el mundo desarrollado, el $21 \%$ en España, y en Castilla y León es del 6-8 \%, y aumenta la probabilidad de infarto agudo de miocardio y/o hemorragia cerebral y amputaciones ${ }^{1}$.

A largo plazo puede tener numerosas complicaciones, entre ellas la nefropatía diabética, la cual suele aparecer en el $50 \%$ de los pacientes a los 20 años de comienzo de la diabetes. La nefropatía diabética es completamente asintomática hasta que se produce un daño grave, y es responsable de que cerca del $30 \%$ de los enfermos entre en diálisis periódica y primera causa de trasplante renal en países occidentales ${ }^{2}$.

Actualmente el trasplante de páncreas riñón es la mejor opción terapéutica para el paciente diabético en diálisis, pero la intervención quirúrgica y la fase postquirúrgica pueden presentar diferentes complicaciones.

Aplicamos el proceso enfermero, que es un método sistematizado de brindar cuidados centrados en el logro de objetivos (NOC), el uso del proceso enfermero complementa el trabajo de los profesionales de otras disciplinas.

Correspondencia:
Consuelo Pérez Rincón
Unidad de diálisis peritoneal. Nefrología. C.A.U. Salamanca
Paseo de San Vicente, 58-182.37007 Salamanca
E-mail: conperin.cpr@gmail.com

Esto requiere una combinación de conocimientos, habilidades y actitudes, por lo tanto, la enfermería cumple un papel importante en la vigilancia de la aparición de estas complicaciones, extendiendo esta función a la realización de las intervenciones necesarias para evitarlas.

El objetivo principal de nuestro caso fue proporcionar cuidados de calidad al paciente aplicando dicho proceso.

\section{Descripción del caso}

Varón de 48 años con IRC por nefropatía diabética en tratamiento sustitutivo con hemodiálisis desde el 27 de octubre del año 2011.

\section{Antecedentes:}

Diabetes mellitus tipo I diagnosticada a los 9 años de edad.

\section{Hiperlipemia.}

Hiperparatiroidismo secundario a nefropatía diabética. Neumonía en dos ocasiones hasta julio del año 2012. Profilaxis de TBC por mantoux positivo.

Parotiditis en la infancia.

EPOC.

Síndrome de robo de la FAVI.

Intervenido de granuloma en lengua hace más de 10 años.

Exfumador desde hace 4 años, de dos paquetes al día durante 30 años.

Vida laboral activa, en la actualidad.

\section{Enfermedad actual:}

Se realiza el ingreso del paciente en la unidad en febrero de 2013 , como candidato para someterse a trasplante simultáneo de páncreas-riñón de donante cadáver.

Las intervenciones enfermeras para la preparación del paciente siguieron la terminología NIC y posteriormente se traslada a quirófano. 
El trasplante de páncreas se realiza sin incidencias, se descubren los vasos iliacos en la parte exterior, que servirán para unirlos a los del donante. Luego se une el duodeno del donante al intestino delgado del receptor, siendo esta la técnica de derivación más funcional y asociada a un menor número de complicaciones (figura 1).

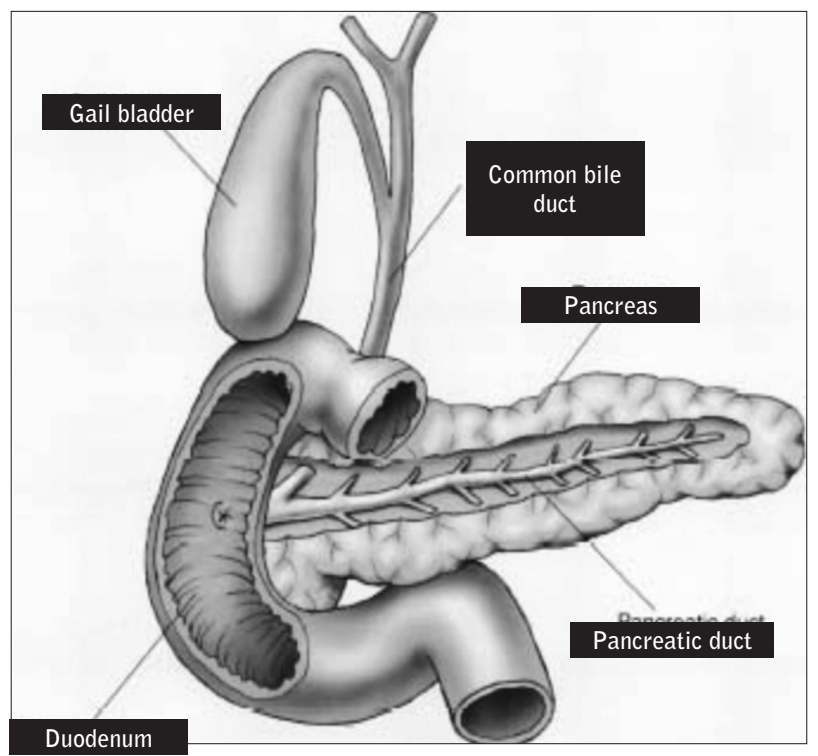

Figura 1. Esquema de las vías biliar y pancreática.

No sucede lo mismo con el trasplante renal, el cual será implantado en el lado izquierdo e inferior del abdomen, usándose los mismos vasos sanguíneos de ese lado, es decir, anastomosis de arteria renal a arteria iliaca y vena renal a vena iliaca ${ }^{3}$ (figura 2), pero en este caso no se obtiene buena perfusión renal con deterioro del injerto renal, que finalmente se deshecha, y se procede a realizar el trasplante con un segundo riñón.

Previamente el servicio de cirugía vascular procedió a ampliar el calibre de la arteria iliaca izquierda con implante de vena safena derecha, sufriendo trombosis de dicha arteria, produciéndose una disminución del riego del miembro inferior izquierdo, que es valorado y resuelto, consiguiéndose que los pulsos femoral y poplíteo estén conservados.

Posteriormente ingresa en UCI durante 12 días, después de los cuales es trasladado a nuestra unidad, donde permanecerá hasta el día 29 sufriendo las siguientes complicaciones:

- Una limitación de la amplitud de movimientos debida a Isquemia de la extremidad inferior izquierda.

- Rabdomiolisis.

- Síndrome compartimental tibial anterior y posterior, precisando una fasciotomia tibial anterior.

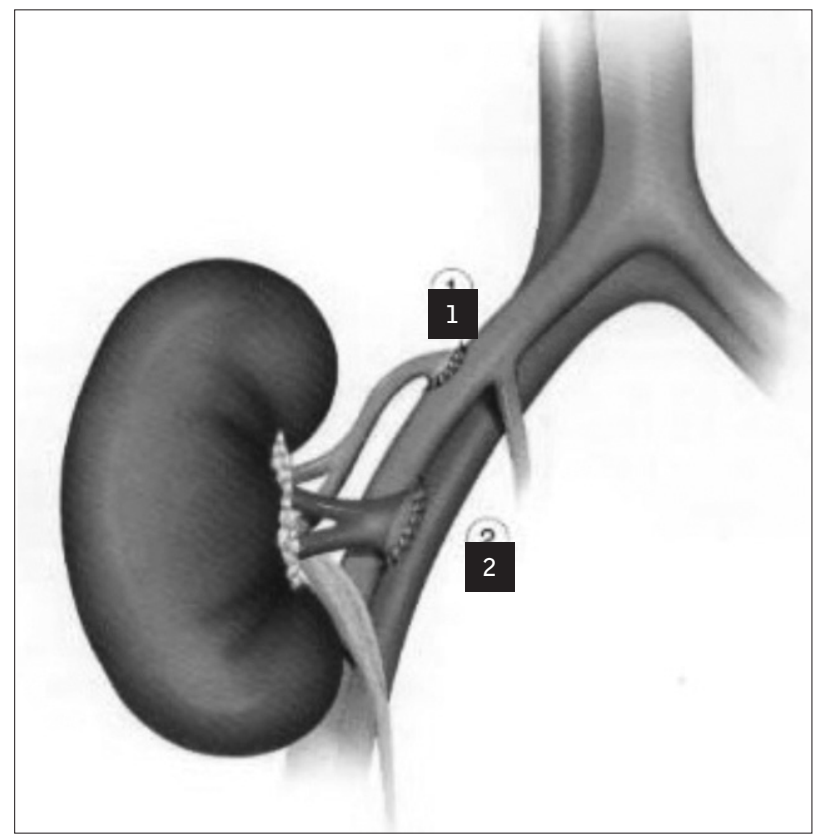

Figura 2. Imagen que muestra las anastomosis de arteria renal a arteria iliaca y vena renal a vena iliaca del implante renal.

- Neuropatía radial y/o del mediano.

- Alteración de las defensas primarias.

- Infección de la herida quirúrgica.

- Infección del drenaje pancreático.

- Reacción anafiláctica secundaria a medicación.

\section{Valoración según las 14 necesidades de Virginia Henderson:}

1.- Respirar normalmente.

El paciente no fuma y la vía aérea es permeable.

2.- Comer y beber.

Mastica sin dificultad, traga sin dificultad.

3.- Eliminación (Urgencia urinaria).

El enfermo es portador de sonda vesical tipo Foley de tres luces número 18.

4.- Movilización.

Se detecta una limitación de la amplitud de movimientos debida a isquemia de la extremidad inferior izquierda, Rabdomiolisis, síndrome compartimental tibial anterior y posterior, neuropatía radial y/o del mediano.

\section{5.- Reposo sueño.}

Expresa quejas verbales por dificultad para conciliar el sueño.

\section{6.- Vestirse.}

Incapacidad para ponerse y quitarse la ropa motivada por la fasciotomía tibial anterior.

7.- Temperatura.

Dentro de la normalidad. 

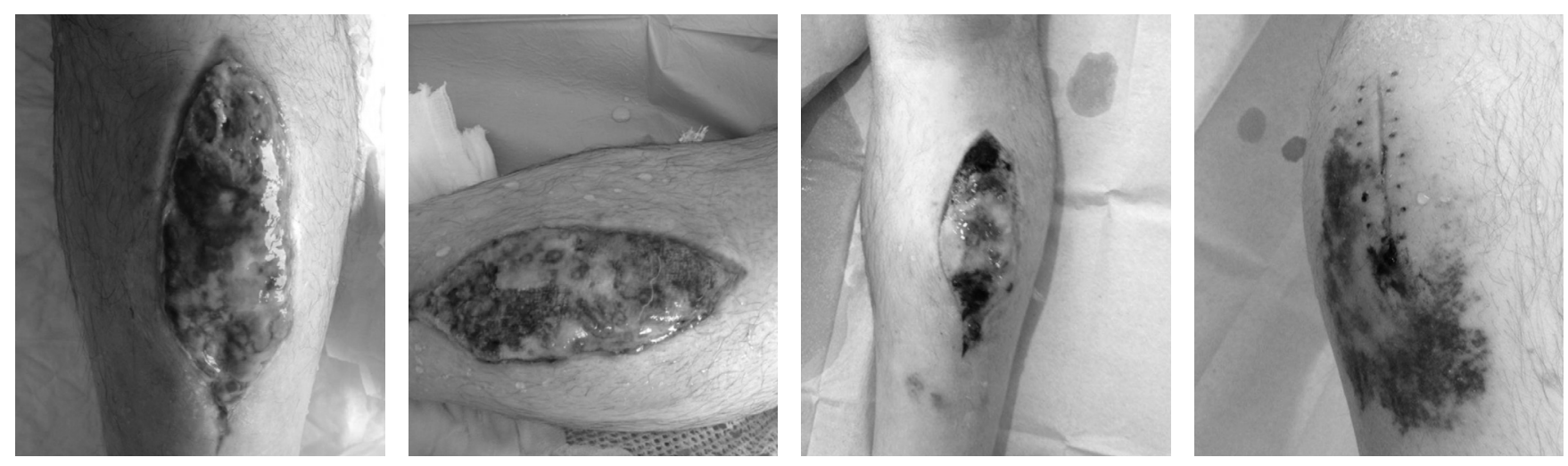

Anexo 1. Iconografía que muestra la evolución de la fasciotomia tibial anterior desde el inicio hasta la cicatrización de la misma. (Siguiendo indicaciones de la Ley de Protección de Datos 15/99 de 13 de diciembre, el paciente ha dado su autorización para la elaboración y publicación del trabajo).

\section{8.- Higiene/piel.}

Estomatitis. Presenta alteración de la superficie de la piel (epidermis) y síndrome compartimental que se resolvió mediante fasciotomía (se presentan imágenes de la evolución en anexo 1).

\section{9.- Seguridad.}

Alteración de las defensas primarias (rotura de la piel, traumatismo de los tejidos, disminución de la acción ciliar), infección de la herida quirúrgica, infección del drenaje pancreático (cultivo positivo de estafilococo hemolítico y pseudomonas). Reacción anafiláctica secundaria al Meropenen, se administra Metilprednisolona.

\section{0.- Comunicación.}

La comunicación con la familia fue buena y se adaptó a los cambios.

\section{1.-Valores y creencias.}

Se muestra capaz de afrontar la situación actual.

\section{2.-Trabajar y realizarse.}

Convivencia habitual. Expresión de percepciones que reflejan una alteración de la visión del propio cuerpo en cuanto a su aspecto, estructura y función.

13.- Actividades lúdicas.

Tiene aficiones de entretenimiento.

14.- Aprender.

El cuidador que se hará cargo del paciente en su domicilio muestra capacidad y disposición para el aprendizaje. Muestra un alto conocimiento de la enfermedad.

A continuación reseñamos el plan de cuidados en este cuadro, a tenor de las necesidades del paciente.

Nanda-Noc-Nic ${ }^{(4)}$, a la llegada a la unidad de trasplante.

\begin{tabular}{|c|c|c|}
\hline NANDA ${ }^{(5)}$ & $\operatorname{NOC}{ }^{(6)}$ & NIC ${ }^{(7)(8)}$ \\
\hline $\begin{array}{l}00114 \text { - Síndrome de estrés del traslado } \mathrm{r} / \mathrm{c} \text { Trasladarse de un } \\
\text { entorno a otro y el deterioro del estado de salud } \mathrm{m} / \mathrm{p} \text { Inseguri- } \\
\text { dad y preocupación }\end{array}$ & $\begin{array}{l}1302 \text { - Afrontamiento de } \\
\text { problemas }\end{array}$ & 5270 - Apoyo emocional \\
\hline $\begin{array}{l}00043 \text { - Protección inefectiva r/c Perfiles hematológicos anor- } \\
\text { males (leucopenia) y con medicamentos (inmunosupresores) } \\
\mathrm{m} / \mathrm{p} \text { Deficiencia Inmunitaria y deterioro de la cicatrización }\end{array}$ & 0702 - Estado inmune & $\begin{array}{l}6550 \text { - Protección contra las } \\
\text { infecciones } \\
6540 \text { - Control de infecciones }\end{array}$ \\
\hline $\begin{array}{l}00045 \text { - Deterioro de la mucosa oral r/c Inmuno-supresión m/p } \\
\text { Palidez de las encías o de las mucosas }\end{array}$ & 1100 - Higiene bucal & 1720 - Fomentar la salud bucal \\
\hline $\begin{array}{l}00026 \text { - Exceso de volumen de líquidos r/c Compromiso de } \\
\text { los mecanismos reguladores } \mathrm{m} / \mathrm{p} \text { Disnea, aumento de la PVC, } \\
\text { edema, aumento de peso en corto periodo de tiempo }\end{array}$ & $\begin{array}{l}0600 \text { - Equilibrio electrolítico y } \\
\text { ácido base }\end{array}$ & $\begin{array}{l}4170 \text { - Manejo de la híper-volemia } \\
4120 \text { - Manejo de líquidos } \\
2020 \text { - Monitorización de electrólitos } \\
154130 \text { - Monitorización de líquidos }\end{array}$ \\
\hline
\end{tabular}




\section{[ Consuelo Pérez Rincón, et al ]}

Aplicación de la terminología nanda-noc-nic en un paciente trasplantado de páncreas riñón

00100 - Retraso en la recuperación quirúrgica r/c Infección postoperatoria de la zona quirúrgica $\mathrm{m} / \mathrm{p}$ Evidencia de interrupción de la curación de la herida quirúrgica

00179 - Riesgo de glucemia inestable r/c Manejo de la

medicación circulación m/p Alteración de la superficie de la piel

00004 - Riesgo de infección r/c Diabetes mellitas, traumatismo tisular, inmuno supresión, procedimientos invasivos

00085 - Deterioro de la movilidad física r/c Dolor y deterioro neuromuscular m/p Limitación de la amplitud de movimiento

00198 - Trastorno del patrón del sueño r/c Falta de intimidad, iluminación e interrupciones para administrar terapias y controles
1103 - Curación de la herida: por segunda intención

2300 - Nivel de glucemia

1103 - Curación de la herida: por segunda intención

1924 - Control del riesgo: proceso infeccioso

1842 - conocimiento: control de la infección

1609 - Conducta terapéutica: enfermedad o lesión

0703 - Severidad de la infección

0208 - Movilidad

0200 - Ambular

2101 - Dolor: efectos nocivos
0703 - Severidad de la infección

2120 - Manejo de la híper-glucemia 2380 - Manejo de la medicación

2314 - Administración de medicación intravenosa

2317 - Administración de medicación: subcutánea

3660 - Cuidados de las heridas

2316 - Administración de medicación tópica

6540 - Control de infecciones

3660 - Cuidados de las heridas

3440 - Cuidados del sitio de incisión

3662 - Cuidados de las heridas: drenaje cerrado

4220 - Cuidados del catéter central insertado periféricamente

1876 - Cuidados del catéter urinario

1870 - Cuidados del drenaje

2380 - Manejo de la medicación

6550 - Protección contra infecciones

0840 - Cambio de posición

0221 - Terapia de ejercicio: ambulación

0200 - fomento de ejercicios

1400 - Manejo del dolor

00217 - Riesgo de respuesta alérgica r/c Fármacos

00108 - Déficit de autocuidado: baño/ higiene r/c Deterioro músculo-esquelético $\mathrm{m} / \mathrm{p}$ Incapacidad para acceder al cuarto de baño e incapacidad para lavarse el cuerpo
0301 - Autocuidados: baño

2102 - Nivel del dolor
1800 - Ayuda al autocuidado

1801 - Ayuda con los cuidados: baño/ higiene

1610 - Baño

1400 - Manejo del dolor

5520 - Facilitar el aprendizaje

2380 - Manejo de la medicación

5606 - Enseñanza individual

5616 - Enseñanza de medicamentos prescritos

4480 - Facilitar la auto responsabilidad
1811 - Conocimiento actividad prescrita

1813 - Conocimiento: del régimen terapéutico interés en el aprendizaje m/p Manifiesta interés en el aprendizaje 
Los cuidados consisten desde controlar y detectar las posibles complicaciones tardías, derivadas de la intervención quirúrgica, realizar educación sanitaria y llevar a cabo el tratamiento, hasta la resolución de las complicaciones precoces posteriores a la intervención quirúrgica.

A los 29 días, tras la administración de los cuidados definidos en la nomenclatura Nanda-Noc-Nic, y viendo que la evolución clínica ha sido satisfactoria, se procede a la intervención 7370, planificación del alta, trasladándose el paciente a su domicilio.

\section{Conclusión}

La utilización NANDA-NOC-NIC, permite adecuar las intervenciones enfermeras y llevar a cabo una buena aplicación de los cuidados.

Recibido: 15 enero 2016

Revisado: 30 enero 2016

Modificado: 2 febrero 2016

Aceptado: 10 febrero 2016

\section{Bibliografía}

1. Tébar Massó FJ, Escobar Jiménez F. La diabetes Mellitus en la práctica clínica. Madrid: Ed. Médica Panamericana; 2009.

2. Mauricio D. Estado actual de la prevención de la diabetes mellitus tipo 1. Av. Diabetol. 2001; 17: 145-155.

3. Verdejo Vivas J. Trasplante de páncreas. Real Academia de Medicina de Granada. Disponible en: dialnet.unirioja.es/descarga/articulo/1227039. pdfhttps://www.google.es/search?q=)+Juan+ver dejo+vivas+cirujano.+Acad\% $3 \%$ A 9 mico+ numerario+de+la+Real+Academia+de+Medici na+de+Granada.\&oq=)+Juan+verdejo+vivas+ cirujano.+Acad\%C3\%A9mico+numerario+ $\mathrm{de}+\mathrm{la}+\mathrm{Real}+\mathrm{Academia}+\mathrm{de}+$ Medicina $+\mathrm{de}+\mathrm{Gra}$ nada. \&aqs=chrome..69i57.1402j0j8\&sourceid= chrome\&espv=210\&es_sm=93\&ie=UTF-8http:// webcache.googleusercontent.com/search? $q=c a$ che:pDrzuYbd5J0J:dialnet.unirioja.es/descarga/ articulo/1227039.pdf $+\& c d=2 \& h l=e s \& c t=c l n k \&$ gl=es

4. Johnson M, Bulechek G, Butcher H, Mccloskey Dochterman J, Maas M, Moorhead S, Swanson E. Interrelaciones Nanda -noc-nic. 2 ed. Madrid: Elsevier; 2006.

5. NANDA International. Diagnósticos enfermeros: definiciones y clasificación 2012-2014. Hedman TH, editora. Madrid: Elsevier; 2012.

6. Moorhead S. Clasificación de resultados de enfermería (NOC). Johnson M, Maas ML, Moorhead S, Swanson E, editores. 5 ed. Madrid: Elsevier; 2013.

7. Bulechek GM. Clasificación de intervenciones de enfermería (NIC). Bulechek GM, Butcher HK, McCloskey-Dochterman J, editores. 5 ed. Madrid: Elsevier; 2013.

8. Rifa Ros R, Olive Adrados C, Lamoglia Puig M. Lenguaje NIC para el aprendizaje teórico-práctico en Enfermería. 2 ed. Madrid: Elsevier; 2013. 